\title{
Induction of a disintegrin and metalloprotease 33 during embryonic lung development and the influence of IL-13 or maternal allergy
}

\author{
Hans Michael Haitchi, MD, PhD, ${ }^{a}$ David J. P. Bassett, PhD, ${ }^{c}$ Fabio Bucchieri, MD, ${ }^{a}$ Xiufeng Gao, MS, ${ }^{c}$ \\ Robert M. Powell, PhD, ${ }^{a}$ Neil A. Hanley, MD, PhD, ${ }^{b}$ David I. Wilson, MD, PhD, ${ }^{b}$ Stephen T. Holgate, MD, DSc, \\ and Donna E. Davies, PhD ${ }^{\mathbf{a}} \quad$ Southampton, United Kingdom, and Detroit, Mich
}

Background: Asthma pathogenesis involves gene and environmental interactions. A disintegrin and metalloprotease 33 (ADAM33)/Adam33 is a susceptibility gene for asthma and bronchial hyperresponsiveness in human beings and mice. ADAM33 is almost exclusively expressed in mesenchymal cells, including mesenchymal progenitors in developing lungs. Objective: Because maternal allergy is a risk factor for asthma, we hypothesized that an allergic environment affects $A D A M 33$ / Adam33 expression during human and mouse lung development.

Methods: Human embryonic/fetal lung (HEL) tissues were collected from first-trimester terminations of pregnancy. These were processed immediately or used for explant culture \pm IL13. MF1 mice or ovalbumin-sensitized A/J mice (Bronchial hyperresponsivness (Bhr)1/Adam33 locus-positive) were timemated and challenged with ovalbumin (A/J mice only) during pregnancy. Lungs were harvested at different times during gestation and post partum. ADAM33/Adam33 expression was analyzed by using reverse transcriptase quantitative polymerase chain reaction and Western blotting.

Results: ADAM33 mRNA was detectable in HELs in the pseudoglandular stage of development and showed a significant increase from 7 to 9 weeks postconception. IL-13 significantly suppressed $A D A M 33$ mRNA in HEL explants. In developing murine lungs, Adam33 mRNA and protein expression increased significantly in the early pseudoglandular stage and showed another large increase post partum. In A/J mice, maternal

\footnotetext{
From ${ }^{a}$ the Roger Brooke Laboratory, Division of Infection Inflammation and Immunity, and $b^{b}$ the Centre for Human Development, Stem Cells and Regeneration, Human Genetics Division, School of Medicine, University of Southampton, UK; and ${ }^{\mathrm{c}}$ the Department of Family Medicine and Public Health Sciences, School of Medicine, Wayne State University, Detroit.

Disclosure of potential conflict of interest: D. J. P. Bassett and X. Gao have received research support from the Michigan University Challenge Initiative, Synairgen Research Ltd, and Wayne State University Research Enhancement. D. I. Wilson has received research support from the Engineering and Physical Sciences Research Council UK. The rest of the authors have declared that they have no conflict of interest.

Supported by the Asthma, Allergy and Inflammation Research (AAIR) Charity, the British Lung Foundation, the Medical Research Council, and the Roger Brooke Charitable Trust, United Kingdom; and Research Enhancement Funds, Wayne State University, Detroit, Mich.

Received for publication December 23, 2008; revised May 14, 2009; accepted for publication June 19, 2009.

Available online August 10, 2009

Reprint requests: Hans Michael Haitchi, MD, PhD, Division of Infection, Inflammation and Immunity, School of Medicine, University of Southampton, Southampton General Hospital, MP 810, Level F, South Academic Block, Tremona Road, Southampton SO16 6YD, United Kingdom. E-mail: hmha@soton.ac.uk.

0091-6749/\$36.00

(C) 2009 American Academy of Allergy, Asthma \& Immunology

doi:10.1016/j.jaci.2009.06.026
}

allergy significantly suppressed Adam33 mRNA in lungs of newborn pups, whereas processed Adam 33 protein increased and several smaller isoforms were detected.

Conclusion: Adam33/Adam33 shows 2 significant increments in expression during lung morphogenesis, suggesting important developmental regulation. The ability of maternal allergy or exogenous IL-13 to suppress Adam33/ADAM33 mRNA but enhance Adam 33 processing suggests a gene-environment interaction that may be relevant for asthma pathogenesis. (J Allergy Clin Immunol 2009;124:590-7.)

Key words: ADAM33, embryoniclfetal, lung development, maternal allergy, environment gene interaction, geNorm analysis

A disintegrin and metalloprotease $(A D A M) 33$ is an asthma and chronic obstructive pulmonary disease susceptibility gene with single nucleotide polymorphisms strongly associated with asthma, bronchial hyperresponsiveness (BHR), ${ }^{1}$ and decline in lung function over time. ${ }^{2,3}$ Furthermore, ADAM33 single nucleotide polymorphisms predict low lung function in children ages 3 and 5 years, ${ }^{4}$ suggesting that the influences of ADAM33 commence early in life. The mouse ortholog of ADAM33 (Adam33) shares $70 \%$ similarity in the amino acid sequence, ${ }^{5}$ and Adam33 is close to the trait locus for bronchial hyperresponsiveness (Bhrl). ${ }^{6}$ Adam33 is highly expressed in adult lung, heart, and brain. $^{7}$ Unlike other members of the ADAM family, ADAM33 shows almost exclusive expression in smooth muscle-containing organs and no expression in organs or cells derived from epithelium. ${ }^{1,8,9}$ However, a soluble form of ADAM33 (sADAM33) has been identified in bronchoalveolar lavage (BAL) fluid from subjects with asthma, where its levels are inversely correlated with lung function. ${ }^{10}$

ADAM33/Adam33 is a member of the multifunctional ADAM family of $\mathrm{Zn}^{2+}$-dependent metalloproteases. The protein is composed of the signal sequence, pro-, metalloprotease-, disintegrin-, cysteine-rich-, epidermal growth factor-like-, transmembrane-, and cytoplasmic domains, to which specific functions have been attributed. ${ }^{5}$ Full-length ADAM33/Adam33 is synthesized as a proenzyme that is inactivated by a cysteine switch mechanism. ${ }^{11}$ Cleavage of the pro-domain by a furin-type protease results in activation of the enzymatically active metalloprotease enzyme, ${ }^{11,12}$ which is proangiogenic ${ }^{12}$ and can catalyze the shedding of a mutant form of CD23. ${ }^{13}$ The ADAM33 disintegrin domain can also interact with the lymphocyte $\alpha_{9} \beta_{1}$ integrin and can mediate cell adhesion. ${ }^{14}$ Ectodomain shedding of ADAM33 to yield sADAM33 is enhanced by TGF- $\beta .^{12}$

The role of $A D A M 33 / A d a m 33$ in embryonic lung development has not been elucidated. In human fetal lung, ADAM33 expression has been shown in the mesenchymal progenitor 
Abbreviations used

ADAM: A disintegrin and metalloprotease

$\alpha S M A: \alpha$-Smooth muscle actin

Atp5b: ATP synthase beta subunit

BAL: Bronchoalveolar lavage

BHR: Bronchial hyperresponsiveness

Cycl: Cytochrome c-1

E: Embryonic day

Gapdh: Glyceraldehyde-3-phosphate dehydrogenase

HEL: Human embryonic/fetal lung

$H K G$ : Housekeeping gene

rRNA: Ribosomal RNA

RT-qPCR: Reverse transcriptase quantitative polymerase chain reaction

sADAM33: Soluble a disintegrin and metalloprotease 33

UK: United Kingdom

cells at both mRNA and protein levels, ${ }^{15}$ as well as in embryonic lung MRC-5 fibroblasts. ${ }^{8,16}$ Using a cDNA panel of whole mouse embryos at day 8.5 , day 9.5 , day 12.5 , and day 19 , semiquantitative PCR revealed the highest expression of Adam33 mRNA at embryonic day $19 .^{7}$ Analysis of offspring (Adam $33^{-1-}$ or Adam $33^{+/-}$) from heterozygous breeding pairs did not reveal gross morphologic differences from the wild-type mice, and histologic examination did not show apparent differences in the major organs. ${ }^{17}$ However, in this study, the function of Adam33 might have been compensated by other Adam or matrix metalloproteinases. Furthermore, it is not known whether there were any differences in morphology and histology during the embryonic and fetal stages of organ development, because this was not evaluated. $^{17}$

Although asthma is a complex disease involving a number of susceptibility genes, disease expression is influenced by a range of environmental factors, including some that appear to act very early in life via maternal influences. For example, maternal atopy/ allergy is a strong risk factor for development of BHR and asthma early in life, ${ }^{18}$ suggesting that a maternal allergic environment has an effect on lung development in utero. Therefore, our objective was to study the expression of ADAM33 in developing human lungs and to model the effect of maternal allergy with IL-13 or to study the effect of a maternal allergic environment in vivo by using a genetically susceptible $\mathrm{A} / \mathrm{J}$ (Bhrl/Adam33 locus-positive) mouse model.

\section{METHODS}

Additional details of all Methods can be found in this article's Online Repository at www.jacionline.org.

\section{Human and murine embryonic/fetal lungs}

Human embryonic/fetal lung (HEL) tissues (7 to 9 weeks postconception) were from first-trimester terminations after obtaining informed ethical approval and written consent. HEL tissue was either freshly homogenized or used for explant culture. MF1 mice (age 6 weeks; Harlan UK Ltd, Bicester, United Kingdom [UK]) were time-mated by detection of a vaginal plug. Gravid uteri were removed under sterile conditions and embryos (see this article's Fig E1 in the Online Repository at www.jacionline.org) killed according to the schedule 1 method. Maternal adult, embryonic, and post partum lungs, hearts, and brains were processed for RNA analysis.

\section{Mouse sensitization, mating, and exposure experiments}

Female A/J mice were sensitized by intraperitoneal injection with $0.2 \mathrm{~mL}$ $0.9 \%$ sterile isotonic saline containing $10 \mu \mathrm{g}$ ovalbumin and $2 \mathrm{mg}$ aluminum hydroxide at day 21 and at day 7 before mating. After mating, the mice were exposed to either saline (control) or ovalbumin ( $1 \% \mathrm{wt} / \mathrm{vol}$ in sterile isotonic saline) aerosols in a nose-only exposure system for a period of 1 hour per day, 3 days per week, for 3 weekly cycles. Lung inflammation was confirmed by using BAL (see this article's Fig E2 in the Online Repository at www.jacionline.org). Pregnant mice were anesthetized for the removal of the embryos and harvesting of lung tissue into RNAlater (Ambion, Inc; Sigma Chemical Co, St Louis, Mo). Tissue was homogenized in TRIzol Reagent (Invitrogen Ltd, Paisley, UK) for RNA/protein extraction and reverse transcriptase quantitative polymerase chain reaction (RT-qPCR)/Western blotting.

\section{RNA extraction and analysis}

Tissues were homogenized (ribolysed) by using a Hybaid RiboLyser Cell Disrupter (Thermo Life Sciences, Hybaid, UK). The homogenate was processed for RNA extraction by using the TRIzol Reagent protocol and any genomic DNA removed by treatment with deoxyribonuclease (DNase) (Ambion, Inc, Warrington, UK). RNA was reverse transcribed and analyzed for expression of ADAM33/Adam33 and $\alpha$-smooth muscle actin $(\alpha S M A / \alpha S m a)$ mRNA by quantitative PCR (see this article's Table E1 in the Online Repository at www.jacionline.org). Relative gene expression was analyzed by using the $\Delta \Delta \mathrm{C}_{\mathrm{T}}$ method relative to ACTIN- $\beta$ (ACTB) in the human tissue and relative to the geometric mean of 3 housekeeping genes (based on geNorm analysis; see this article's Table E2 and Fig E3, $A$ and $B$, in the Online Repository at www.jacionline.org): glyceraldehyde-3-phosphate dehydrogenase (Gapdh), ATP synthase beta subunit (Atp5b), and cytochrome c-1 (Cycl) in the mouse.

\section{Protein extraction and analysis}

Total protein was isolated from corresponding samples used for RNA extraction with the TRIzol Reagent protocol. The protein was dissolved in $1 \mathrm{x}$ SDS sample buffer and Western blotting was performed by using antibodies against the ectodomain of Adam33 (AF2434; R\&D Systems Europe Ltd, Abingdon, UK), and Actin- $\beta$ (ab8229; Abcam plc, Cambridge, UK), as previously described. ${ }^{15}$

\section{HEL explant culture}

Human embryonic/fetal lungs were cut into pieces of tissue 1 to $2 \mathrm{~mm}$ and embedded in 50 to $60 \mu \mathrm{L}$ Growth Factor Reduced Matrigel Matrix (BD Biosciences, Oxford, UK) in serum-free medium in transwells. The explants were incubated for as long as 18 days in the absence or presence of IL-13 ( $1 \mathrm{ng} / \mathrm{mL}$; R\&D Systems Europe Ltd, Abingdon, UK). The tissue was harvested into TRIzol Reagent for RNA extraction. Phase contrast images were taken by using a LEICA DM IRB inverted microscope (Leica Microsystems GmbH, Wetzlar, Germany).

\section{Statistics}

Data analyses were performed by using SigmaStat and SigmaPlot (Systat Software Inc, Hounslow, UK). Where data were normally distributed, they were compared by using the Student $t$ test or, for multiple groups, a 1-way ANOVA and multiple comparison Bonferroni $t$ test. Where the test failed normality criteria, nonparametric tests were performed. Significance was reached when $P \leq .05$.

\section{RESULTS \\ ADAM33 mRNA expression in HELs in vivo}

To study the expression of ADAM33 mRNA in HELs, RNA was extracted from fresh HELs obtained 7 to 9 weeks postconception. Comparisons during the early pseudoglandular stage of lung development suggested that $A D A M 33$ mRNA expression increased significantly from 7 to 9 weeks postconception (Fig 1, A). When HEL 

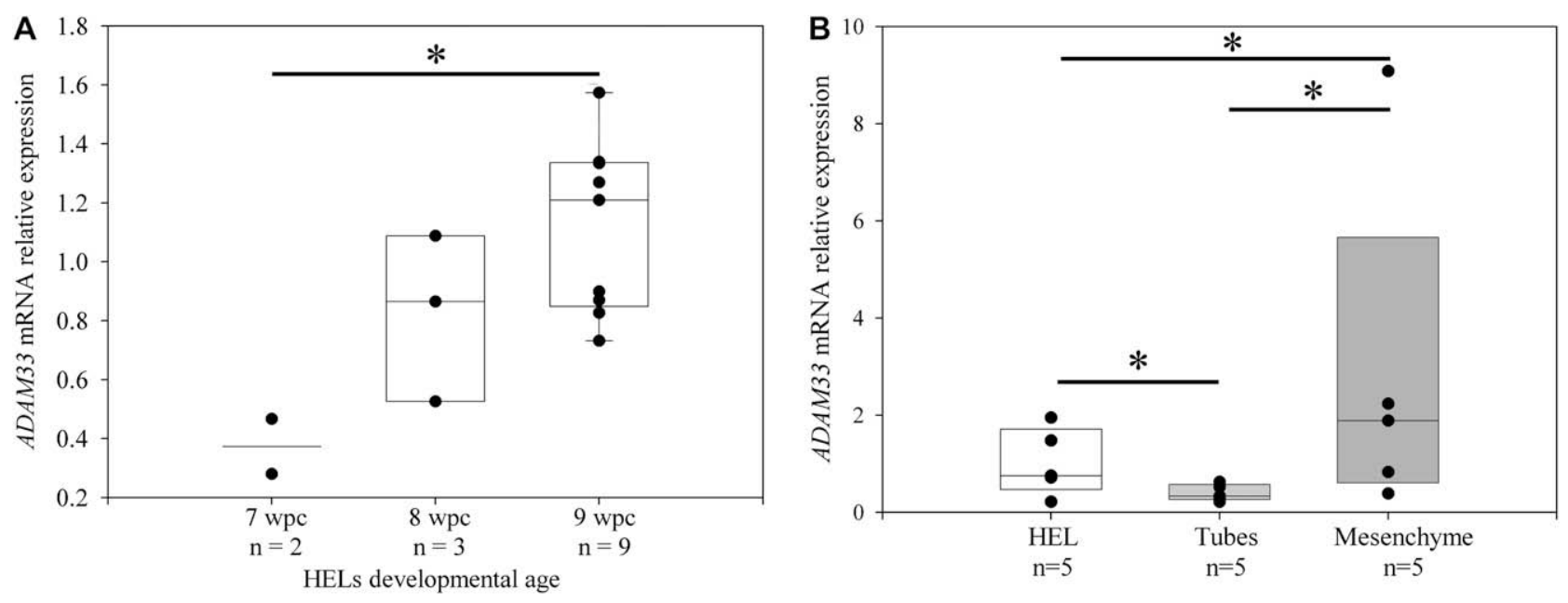

FIG 1. ADAM33 mRNA expression relative to $A C T I N-\beta(A C T B)$ mRNA (A) in vivo in 7 to 9 weeks postconception (wpc) HELs $(\mathrm{n}=2-9)$ and $(\mathrm{B})$ in HELs $(\mathrm{n}=5)$ dissected into tubular airway (tubes) and mesenchymal (mesenchyme) structures (1-way ANOVA and multiple comparison Bonferroni $t$ test [A], Kruskal-Wallis 1 -way ANOVA on ranks and multiple comparison Student-Newman-Keuls method $\left.[B],{ }^{*} P<.05\right)$.
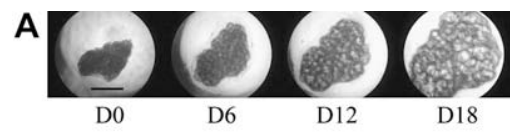

B

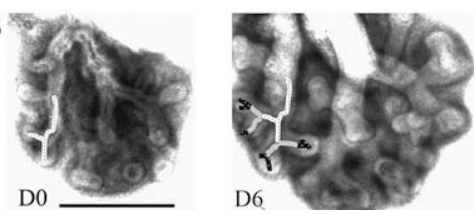

FIG 2. Phase contrast microscopy of HEL explants cultured (A) for 6 to 18 days $(D)$ and (B) time-lapse microscopy of $\mathrm{HEL}$ explants cultured for 8 days, showing a snap shot at day 0 (D0) and day 6 (D6). Lines show primitive airway branches and buds at day 0 with 2 generations of branching at day 6 (black bar $=10 \mathrm{~mm}$ ).

tissues were dissected into the tubular structure and the mesenchyme surrounding these structures, ADAM33 mRNA expression was significantly higher in the mesenchyme (Fig 1,B), confirming our previous data, in which we could show almost exclusive expression of ADAM33 in the mesenchymal progenitor cells. ${ }^{15}$

\section{ADAM33 expression in HEL explant cultures in the presence of IL-13}

To model the effect of the maternal environment on ADAM33 mRNA expression in HEL development, an explant culture model was developed. Pieces of HELs were cultured in Matrigel in transwell culture inserts, where they increased in size and exhibited branching morphogenesis over a period of 18 days (Fig 2, $A$ and $B)$. When the HEL explants were cultured in serum-free medium, $A D A M 33$ and $\alpha S M A$ mRNA increased significantly after 12 and 18 days in culture compared with day 0 (Fig 3, $A$ and $B$ ). An increase in $A D A M 33$ and $\alpha S M A$ mRNA was also detected in HEL explants cultured in the presence of IL-13 $(1 \mathrm{ng} / \mathrm{mL})$, which was used to mimic a maternal allergic environment; however, after 18 days, there was a significant depression in ADAM33 mRNA compared with the lungs cultured in serum-free medium alone (Fig 4, A). In contrast, $\alpha S M A$ mRNA levels, which were used as a measure of smooth muscle content, showed no significant difference (Fig 4,B).

\section{Adam33 mRNA and Adam33 protein expression in mouse embryonic, fetal, juvenile, and adult mouse tissues}

Because it was not possible to study the expression of ADAM33 and the effect of IL-13 on human embryonic/fetal lungs at later stages of gestation, we studied the expression of Adam33 mRNA during mouse development. Initially, outbred MF1 mice were chosen for ease of mating and high number of offspring per litter. Lungs, hearts, and brains were dissected from mouse embryos/fetuses from embryonic day (E) 11 to 19, post partum (P) juvenile mice, and adult mice (AM), and then RNA was extracted. Initially Adam33 mRNA expression was analyzed relative to either $18 S$ ribosomal RNA ( $r R N A$ ) or Gapdh mRNA, both of which are commonly used as housekeeping genes (HKGs) for normalization. However, although the expression profiles were similar, there were inconsistencies in the fold increase and expression profile (see this article's Fig E4, $A$ and $B$, in the Online Repository at www.jacionline.org). Because significant changes in gene expression occur during embryonic development, we were concerned that these inconsistencies were a result of changes in expression of the HKGs. Therefore, we used geNorm analysis to identify the most stably expressed genes during mouse lung development to enable accurate gene quantification.

When the 3 most stably expressed HKGs (Gapdh, Atp5b, and $C y c 1$; Fig E3, $A$ and B) were used for normalization of Adam33 mRNA, it could be seen that Adam33 expression increased in significant steps during mouse lung development (Fig 5, $A$ ). These changes corresponded to the stages of normal lung development (Fig 5, D; Fig E1), with the greatest increases in Adam33 mRNA expression from the early embryonic stage and lung bud formation (E11) to the pseudoglandular stage (E12-16) and again from saccular $(\mathrm{E} 18,19)$ to the alveolar $(\mathrm{P} 5-30)$ and adult stage (AM; $P<.001$ ). $\alpha$ Sma mRNA expression showed a similar 

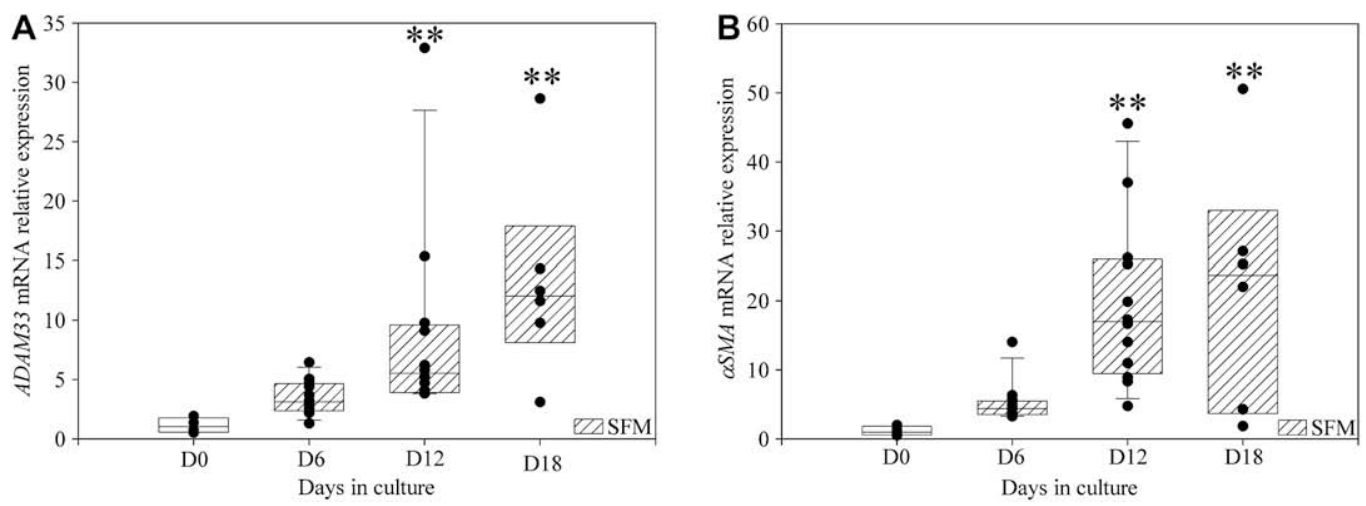

FIG 3. (A) $A D A M 33$ and (B) $\alpha S M A$ mRNA relative expression in vivo at day (D) 0 compared with ex vivo in HEL explants cultured for 6, 12, and 18 days in serum-free medium (SFM) (Kruskal-Wallis 1-way ANOVA on ranks and multiple comparison Dunn method, $\left.{ }^{* *} P<.001\right)$.
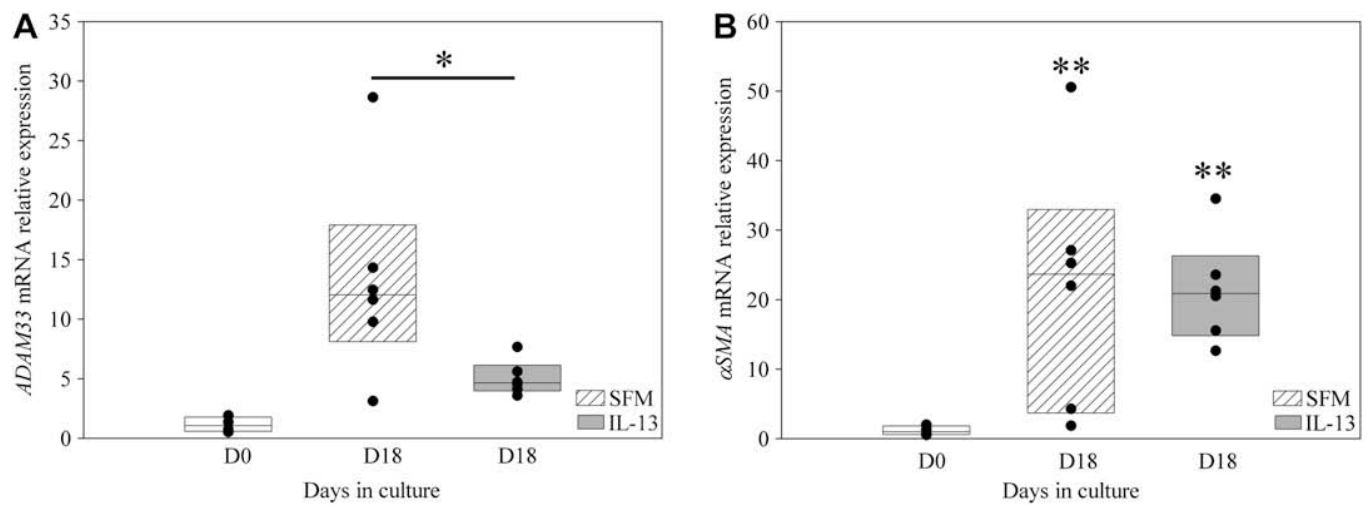

FIG 4. (A) $A D A M 33$ and (B) $\alpha S M A$ mRNA relative expression in vivo at day (D) 0 compared with $\mathrm{HEL}$ explants cultured ex vivo for 18 days in serum-free medium (SFM) plus IL-13 at $1 \mathrm{ng} / \mathrm{mL}$ (Mann-Whitney rank-sum test, ${ }^{*} P \leq .05 ;{ }^{*} P<.001$ vs day 0 , unless otherwise indicated).

pattern with a significant increase in the early stage of embryonic lung development and post partum (Fig 5,B). This contrasts with the transcription factor forkhead box Al (Foxal), another important gene in lung development, ${ }^{19}$ which showed a much lower expression relative to Adam33 and no incremental changes during lung development. ${ }^{20}$ In comparison with developing lungs, Adam33 and $\alpha$ Sma mRNA were much lower and had a different and much flatter pattern of expression in tissue from developing heart and brain, suggesting differential regulation in these 2 organs (see this article's Fig E5, $A-D$, in the Online Repository at www.jacionline.org).

Consistent with the mRNA data, Adam33 protein, normalized to Actin- $\beta$ expression, was also significantly increased in the pseudoglandular stage and again after birth (Fig 5, A, insert, and $C)$. However, most notably, the full-length (pro-) Adam33 protein, which has a molecular weight of approximately $110 \mathrm{kDa}$, was substantially processed at E19 and P9, resulting in a smaller protein of between 90 and $100 \mathrm{kDa}$, which probably represents enzymatically active full-length Adam33.

\section{Influence of an allergic maternal environment on Adam 33 mRNA and Adam33 protein expression in the lungs of offspring}

Maternal atopy is a strong risk factor for developing BHR and asthma $^{18,21,22}$ early in life. To investigate the impact of maternal allergy on Adam33 expression, we used A/J mice (Bhrl locuspositive). ${ }^{6}$ For allergen exposures, mice were sensitized to ovalbumin by intraperitoneal injection 21 days and 7 days before mating (Fig 6, A). The pregnant mothers were then exposed to saline (control) or ovalbumin aerosols in nose-only exposure systems. Exposures were conducted for a period of 1 hour per day, 3 days per week, for 3 weeks. ${ }^{23}$ Fetuses and newborn offspring were killed at 15 or 17 to 19 days postconception and 3 to 5 days post partum (Fig 6, $A$ ) and lungs harvested for RNA analysis. As found in MF1 mice, Adam33 and $\alpha$ Sma mRNA expression increased significantly in A/J mice post partum (Fig 6, B and $C)$. However, in lungs of newborn offspring from mothers with ovalbumin allergy, Adam33 mRNA expression was significantly suppressed $(P=.03$; Fig $6, B)$, whereas $\alpha$ Sma mRNA was not affected (Fig 6, $C$ ).

When we studied Adam 33 protein expression, at 4 days post partum we found more processing of the full-length (pro-) Adam 33 protein in offspring of mothers with ovalbumin allergy and an accumulation of smaller bands suggesting further processing (eg, ectodomain shedding) or degradation of Adam33 (Fig 6, $D$ ); contrary to expectations based on mRNA levels, there was an increase of total Adam 33 protein relative to Actin- $\beta$ in offspring of mothers with ovalbumin allergy (Fig 6, $D$ and $E$ ). At 15 days and 19 days postconception, no difference in the amount or processing of Adam 33 could be detected (data not shown). 
A

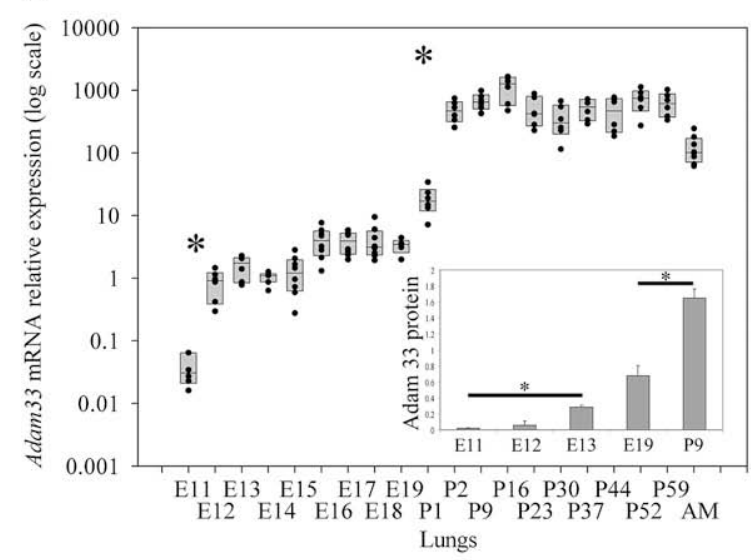

C

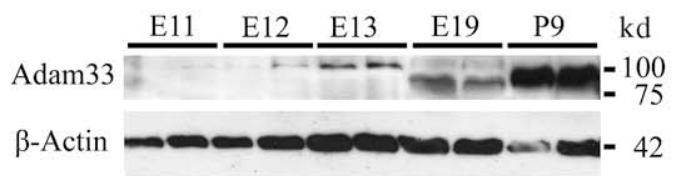

B
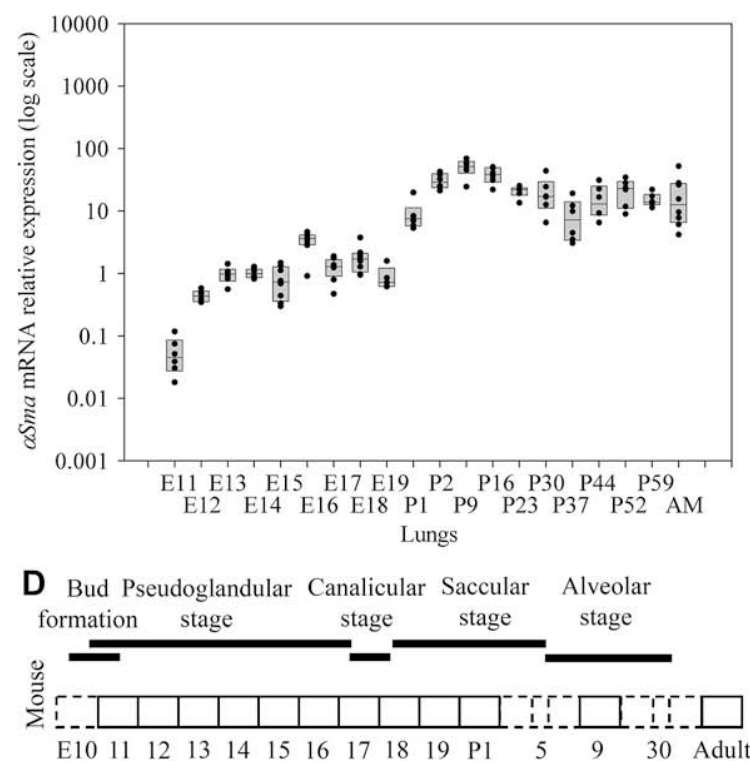

FIG 5. (A) Adam 33 and (B) $\alpha$ Sma mRNA expression (log scale) in vivo relative to the geometric mean of 3 HKGs (Kruskal-Wallis 1-way ANOVA on ranks and multiple comparison Dunn method, ${ }^{*} P<.001$ ). Lungs were harvested from embryonic/fetal (E) days 11 to 19 , post partum $(P)$ days 1 to 59, and adult MF1 mice (AM) for RNA analysis. C, Western blot for Adam33 and Actin- $\beta$ (loading control) from lungs harvested at $\mathrm{E} 11,12,13,19$, and $\mathrm{P} 9$. Adam33 protein relative intensity is shown as an insert in $A$. D, Schematic representation of histologic stages of lung development in the mouse. ${ }^{37,38}$

\section{DISCUSSION}

In this study, we show for the first time that ADAM33/Adam33 expression is developmentally regulated in human and murine lungs. Furthermore, although mRNA expression is suppressed by maternal allergy or exogenous IL-13, in vivo Adam33 protein is increased in lungs from 4-day-old offspring of mothers with ovalbumin allergy, suggesting important gene-environment interactions that may contribute to asthma pathogenesis. We have previously shown that ADAM33 can be found almost exclusively in the mesenchymal progenitor cells that surround the primitive tubular airway structures in human fetal lungs. ${ }^{15}$ RT-qPCR of HELs dissected into the mesenchymal cell mesh and tubular epithelial structures confirmed the predominant expression of ADAM33 mRNA in the mesenchymal progenitor cells. This contrasts with adult human airways, in which ADAM33 protein is localized to the smooth muscle bundles ${ }^{15}$ suggesting a different function in embryonic/fetal lungs compared with adult airways. Although no major effect on lung development was observed in a mouse deficient of Adam $33,{ }^{17}$ this may have been compensated by other Adams or metalloproteases. In view of the expression of ADAM33 in mesenchymal progenitor cells, we suggest that it is involved in controlling their differentiation into smooth muscle, as well as influencing development of other bronchial structures such as the vascular ${ }^{12}$ and neural networks of the airways and the submucosal fibroblasts/myofibroblasts and matrix that make up the airway wall.

The initial analysis of the data of Adam33 mRNA expression in the developing murine lungs using common HKGs (18S rRNA and Gapdh) showed inconsistency in its expression pattern and the fold increase. However, use of 12 different $H K G s$ and geNorm analysis enabled discovery of the 3 most stably expressed HKGs that could be used for mRNA quantitation. This allowed us to demonstrate that Adam33 expression is several hundred-fold higher and shows a different expression pattern in the developing lungs compared with the developing hearts and brains, suggesting a specific role for Adam33 in lung development. Most importantly, however, we were able to show significant stepwise increments in Adam33 and $\alpha$ Sma mRNA expression over the whole period of mouse lung development, especially on entry into the pseudoglandular stage of lung development and again after birth (Fig 5, A). Similar increases were found for Adam33 protein (Fig 5, C), and our Western blot data further indicated that the full-length protein underwent a marked increase in processing from ED19. This suggests that the Adam 33 metalloprotease may become functionally active in response to changes occurring in the perinatal period. Further studies are required to ascertain the factors that regulate its activation and the exact function of Adam33 in this context.

Consistent with this mouse expression data, we also found that ADAM33 mRNA increased during the pseudoglandular stage of normal human lung development in vivo (Fig 1,A). Although it would have been desirable to cover a wider gestational range in human beings, this was not possible for ethical reasons. However, our newly developed HEL explant culture system showed that HEL tissue can be cultured for several weeks, during which period branching morphogenesis is maintained (Fig 2, $A$ and $B$ ), making it a useful tool for studying mechanisms of lung development in human tissue. We also showed by using this HEL explant model that ADAM33 mRNA expression increased significantly over a period of 18 days in culture ex vivo (Fig 3, $A$ ), consistent with the data showing increased expression during lung development in vivo (Fig 1, A). 
A
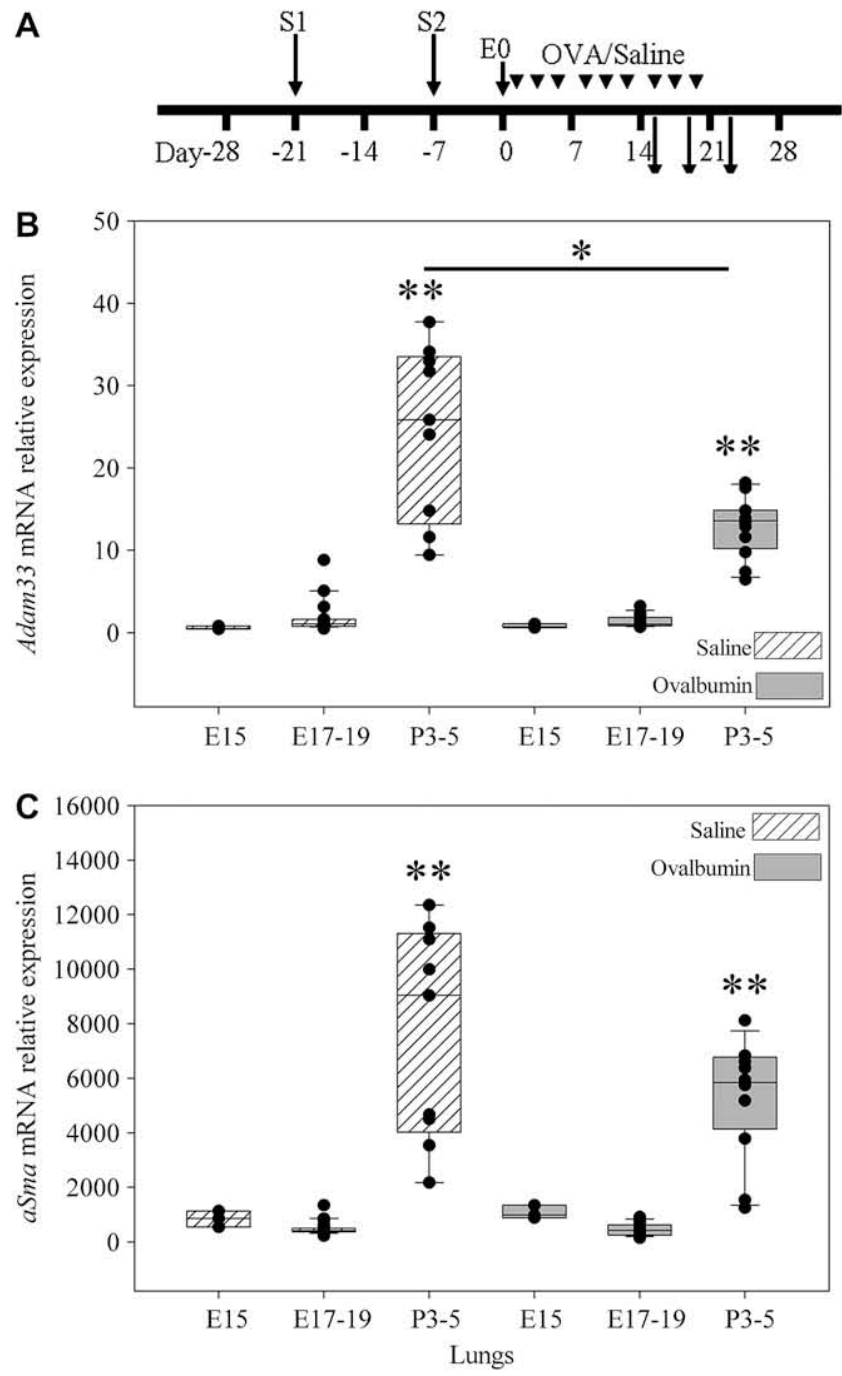

D

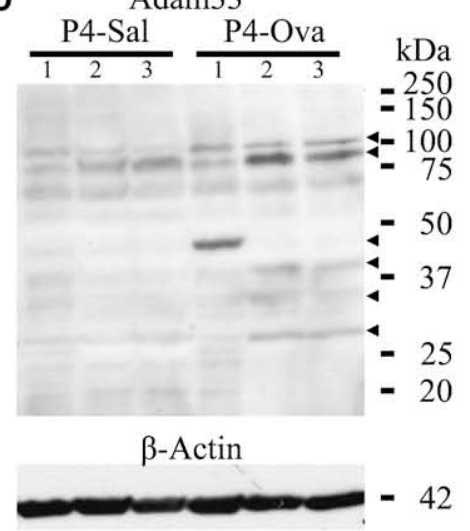

$\mathrm{E}$

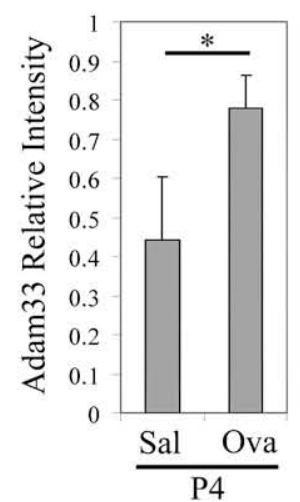

FIG 6. A, A/J mouse exposure experiments: female mice were sensitized (S) with ovalbumin (OVA) before mating and challenged during pregnancy. Lungs from offspring were harvested at embryonic/fetal day $(E) 15,17$ to 19 , and 3 to 5 days post partum (P). B and C, Adam33 and $\alpha$ Sma mRNA expression in vivo in lungs from offspring from saline or OVA-challenged mothers. D and $\mathbf{E}$, Western blot and densitometric analysis of Adam 33 and Actin- $\beta$ (loading control) in vivo in 4 day post partum lungs from offspring of saline (P4-Sal) or OVA (P4-Ova)-challenged mothers. The arrowheads indicate pro-Adam33, processed Adam33, and smaller molecular weight species of Adam33 (Mann-Whitney rank-sum test, ${ }^{*} P<.001$ vs day 15 and $17-19 ; t$ test, ${ }^{*} P<.05$ ).
One possible explanation for the significant increase in the early stages of lung development (embryonic to pseudoglandular stage) might be an association with the spontaneous airway contractions (about $1 / \mathrm{min}$ ) that are known to occur in the early pseudoglandular stage ${ }^{24}$ and can be observed during branching morphogenesis in mouse and human embryonic/fetal lung explant cultures in vitro (see this article's Fig E6, $A$ and $B$, in the Online Repository at www.jacionline.org). These peristaltic movements are thought to promote the growth of the lung buds and developing airways into the surrounding mesenchyme. ${ }^{25}$

Such an association with mechanical stretch may also be the explanation for the increase in Adam33 seen in murine lungs after birth when mechanical stretch from air breathing commences. Breathing movements at and after birth are dramatic changes for the newborn lungs, resulting in significant mechanical forces on the airways, which might also provide the trigger for Adam33 processing.

Maternal allergy is one of many environmental factors, including cigarette smoke, alcohol, toxins or drugs, and diet, that can have an influence on embryonic and fetal lung development and can result in early-life wheezing, which might continue as childhood or adult asthma. ${ }^{18,26-28}$ Because children 3 and 5 years old from a prospective birth cohort study showed an association of impaired lung function with the ADAM33 polymorphism, ${ }^{4}$ we hypothesized that maternal allergy interacted with ADAM33 during lung development. To test our hypothesis in human embryonic/fetal lung, we used an in vitro model with IL-13, a $\mathrm{T}_{\mathrm{H}} 2$ immunoregulatory cytokine that plays an important role in the pathogenesis of allergic asthma and atopy. ${ }^{29} \mathrm{IL}-13$ is centrally involved in the induction of $\mathrm{T}_{\mathrm{H}} 2$ cells and promotion of IgE production; it has also been implicated in airway remodeling in murine lung IL-13 overexpression models, where it causes collagen deposition, mucus cell metaplasia, and emphysema. ${ }^{30}$ Previous studies have suggested that IL-13 production by $\mathrm{CD} 4^{+}$cord blood mononuclear cells might be used to identify newborns from atopic mothers who are at high risk of developing asthma. ${ }^{31}$ During gestation, IL-13 has been localized in trophoblasts of the placenta in the first trimester of pregnancy using in situ hybridization or immunohistochemistry and can be produced by fetal mononuclear cells. ${ }^{32}$ It is also possible that maternal IL-13 protein can cross the placental-fetal barrier, because there is a significant positive correlation between maternal and fetal cord plasma IL-13 concentrations in paired maternal-fetal cord plasma at 32 weeks of gestation. ${ }^{33}$ We therefore decided to model the effect of maternal allergy by adding IL-13 to HELs cultures. This caused a significant suppression of ADAM33 mRNA (Fig 4, A) but not $\alpha S M A$. These results contrast with a previous in vitro study using adult human airway smooth muscle cells in which IL-13 was reported to have no effect on ADAM33 mRNA expression. ${ }^{34}$

To explore further the influence of maternal allergy in vivo, we used a murine model with $\mathrm{A} / \mathrm{J}$ mice in which the quantitative trait locus for bronchial hyperresponsiveness (bhr1) on chromosome 2 is syntenic to human ADAM33 on chromosome $20 \mathrm{p} 13 .{ }^{6}$ Ovalbumin-sensitized and challenged pregnant female A/J mice showed a marked eosinophilic and lymphocytic pulmonary inflammation compared with control mice (Fig E2). When the expression of Adam33 mRNA was studied in the offspring of saline-challenged mice, a significant increase in Adam33 was detected in the lungs from the newborns, confirming the findings in the MF1 mice. Although there was significant suppression of Adam33 mRNA in the lungs of the newborn mice (3-5 days post partum) from 
mothers with allergy compared with saline-challenged control mice (Fig 6, B), we found an increase in the amount and processing of full-length Adam 33 protein in the same lungs and an accumulation of smaller molecular Adam33 species. These may represent further processing of the membrane anchored protein or products of alternative splicing. Because the antibody used recognized the Adam33 ectodomain, the species of 30 to $50 \mathrm{kDa}$ may be similar to sADAM33 found in BAL fluid of subjects with asthma. ${ }^{10}$ The possibility that maternal allergy may lead to generation of sAdam 33 in postnatal lungs of genetically susceptible $A / J$ mice merits further investigation at the functional level. Ideally, this would involve assessment of lung function and airway reactivity, although this is not possible in such young mice.

The finding that Adam33 mRNA is depressed whereas Adam33 protein is increased in the lungs of newborns from mothers with allergy suggests that maternal allergy may independently control Adam33 gene transcription and Adam33 protein translation and/ or stability. Although seemingly paradoxical, it is not unusual to find that mRNA and protein levels are not directly correlated. ${ }^{35}$ After transcription, many factors influence protein levels, including alternative mRNA splicing, mRNA stability, mRNA association with translationally active polyribosomes or inactive monoribosomes, posttranslational protein processing, and stability. In view of the increase in low-molecular-weight species of Adam33 that were detected, it is possible that increased processing and turnover of Adam33 protein in offspring of mouse mothers with allergy drives an increase in translation, even though mRNA levels have been suppressed.

It is known that IL-13 induces TGF- $\beta$ from epithelial cells, ${ }^{36}$ and we have recently found that TGF- $\beta$ suppresses ADAM33 mRNA expression in primary bronchial fibroblasts (unpublished data). However, TGF- $\beta$ also enhances ectodomain shedding of ADAM33, causing the release of sADAM 33. ${ }^{12}$ Together, these TGF- $\beta$-mediated mechanisms might explain how ADAM33/ Adam33 mRNA is suppressed by IL-13 or maternal allergy in the human and murine lung models and why there is an increase in processing/degradation of Adam 33 protein in lungs of offspring of mice with allergy in vivo. If these effects translate into human asthma, the presence of SADAM33 in amniotic fluid or BAL fluid of genetically susceptible young children might reflect the early-life influences of the maternal allergic environment on $A D A M 33$ and may be a predictor for persistent wheezing in young children.

\section{Conclusion}

The expression of ADAM33/Adam33 during lung development would be consistent with a role in airway wall modeling. Our results suggest that the maternal $\mathrm{T}_{\mathrm{H}} 2$ environment and maternally derived IL-13 suppress ADAM33/Adam33 mRNA expression levels but induce an increase in shorter forms of Adam33 protein that may be similar to sADAM33 found in BAL fluid of subjects with asthma. This might affect the structure and/or functional behavior of the developing airway walls in utero and post partum, predisposing to the development of BHR early in life and asthma and chronic obstructive pulmonary disease later in life. Morphologic and physiological studies are now needed to elucidate further this gene-environment interaction and to study the potential effect of shorter (soluble) forms of Adam33 on airway structure and function in early life.
We acknowledge Mrs Jas Barley, Mr Kerry Taylor, and Mr Michael Broome for animal husbandry in the Biomedical Research Facility. For personal ethical reasons, R.M.P. was not involved in any work with human embryonic/fetal tissue.

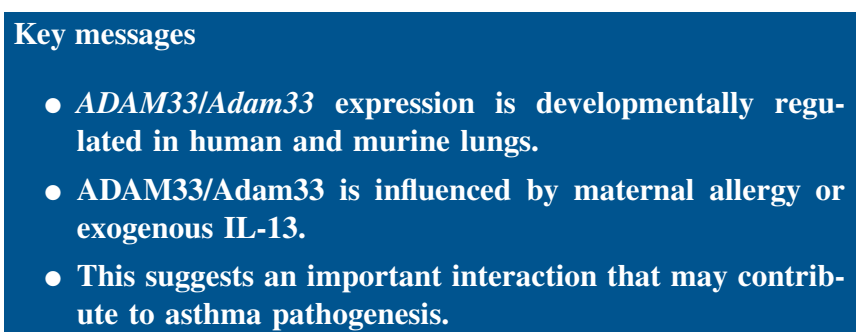

\section{REFERENCES}

1. Van Eerdewegh P, Little RD, Dupuis J, Del Mastro RG, Falls K, Simon J, et al. Association of the ADAM33 gene with asthma and bronchial hyperresponsiveness. Nature 2002;418:426-30.

2. Jongepier H, Boezen HM, Dijkstra A, Howard TD, Vonk JM, Koppelman GH, et al. Polymorphisms of the ADAM33 gene are associated with accelerated lung function decline in asthma. Clin Exp Allergy 2004;34:757-60.

3. van Diemen CC, Postma DS, Vonk JM, Bruinenberg M, Schouten JP, Boezen HM. A disintegrin and metalloprotease 33 polymorphisms and lung function decline in the general population. Am J Respir Crit Care Med 2005;172:329-33.

4. Simpson A, Maniatis N, Jury F, Cakebread JA, Lowe LA, Holgate ST, et al. Polymorphisms in a disintegrin and metalloprotease 33 (ADAM33) predict impaired early-life lung function. Am J Respir Crit Care Med 2005;172:55-60.

5. Yoshinaka T, Nishii K, Yamada K, Sawada H, Nishiwaki E, Smith K, et al. Identification and characterization of novel mouse and human ADAM33s with potential metalloprotease activity. Gene 2002;282:227-36.

6. De Sanctis GT, Merchant M, Beier DR, Dredge RD, Grobholz JK, Martin TR, et al. Quantitative locus analysis of airway hyperresponsiveness in A/J and C57BL/6J mice. Nat Genet 1995;11:150-4.

7. Gunn TM, Azarani A, Kim PH, Hyman RW, Davis RW, Barsh GS. Identification and preliminary characterization of mouse Adam33. BMC Genet 2002;3:2.

8. Umland SP, Garlisi CG, Shah H, Wan Y, Zou J, Devito KE, et al. Human ADAM33 messenger RNA expression profile and post-transcriptional regulation. Am J Respir Cell Mol Biol 2003;29:571-82.

9. Yang Y, Haitchi HM, Cakebread J, Sammut D, Harvey A, Powell RM, et al. Epigenetic mechanisms silence a disintegrin and metalloprotease 33 expression in bronchial epithelial cells. J Allergy Clin Immunol 2008;121:1393-9.

10. Lee JY, Park SW, Chang HK, Kim HY, Rhim T, Lee JH, et al. A disintegrin and metalloproteinase 33 protein in patients with asthma: relevance to airflow limitation. Am J Respir Crit Care Med 2006;173:729-35.

11. Zou J, Zhu F, Liu J, Wang W, Zhang R, Garlisi CG, et al. Catalytic activity of human ADAM33. J Biol Chem 2004;279:9818-30.

12. Puxeddu I, Pang YY, Harvey A, Haitchi HM, Nicholas B, Yoshisue H, et al. The soluble form of a disintegrin and metalloprotease 33 promotes angiogenesis: implications for airway remodeling in asthma. J Allergy Clin Immunol 2008;121: 1400-6.

13. Meng JF, McFall C, Rosenwasser LJ. Polymorphism R62W results in resistance of CD23 to enzymatic cleavage in cultured cells. Genes Immun 2007;8:215-23.

14. Bridges LC, Sheppard D, Bowditch RD. ADAM disintegrin-like domain recognition by the lymphocyte integrins alpha4betal and alpha4beta7. Biochem J 2005; 387:101-8.

15. Haitchi HM, Powell RM, Shaw TJ, Howarth PH, Wilson SJ, Wilson DI, et al. ADAM33 expression in asthmatic airways and human embryonic lungs. Am J Respir Crit Care Med 2005;171:958-65.

16. Garlisi CG, Zou J, Devito KE, Tian F, Zhu FX, Liu J, et al. Human ADAM33: protein maturation and localization. Biochem Biophys Res Commun 2003;301:35-43.

17. Chen C, Huang X, Sheppard D. ADAM33 is not essential for growth and development and does not modulate allergic asthma in mice. Mol Cell Biol 2006;26: 6950-6.

18. Young S, Le Souef PN, Geelhoed GC, Stick SM, Turner KJ, Landau LI. The influence of a family history of asthma and parental smoking on airway responsiveness in early infancy. N Engl J Med 1991;324:1168-73.

19. Wan H, Dingle S, Xu Y, Besnard V, Kaestner KH, Ang SL, et al. Compensatory roles of Foxa1 and Foxa2 during lung morphogenesis. J Biol Chem 2005;280: 13809-16. 
20. Haitchi HM, Yoshisue H, Ribbene A, Wilson SJ, Holloway JW, Bucchieri F, et al. Chronological expression of ciliated bronchial epithelium 1 during pulmonary development. Eur Respir J 2009;33:1095-104

21. Sears MR, Holdaway MD, Flannery EM, Herbison GP, Silva PA. Parental and neonatal risk factors for atopy, airway hyper-responsiveness, and asthma. Arch Dis Child 1996;75:392-8.

22. Arshad SH, Kurukulaaratchy RJ, Fenn M, Matthews S. Early life risk factors for current wheeze, asthma, and bronchial hyperresponsiveness at 10 years of age. Chest 2005;127:502-8.

23. Temelkovski J, Hogan SP, Shepherd DP, Foster PS, Kumar RK. An improved murine model of asthma: selective airway inflammation, epithelial lesions and increased methacholine responsiveness following chronic exposure to aerosolised allergen. Thorax 1998;53:849-56.

24. Jesudason EC, Smith NP, Connell MG, Spiller DG, White MR, Fernig DG, et al Developing rat lung has a sided pacemaker region for morphogenesis-related airway peristalsis. Am J Respir Cell Mol Biol 2005;32:118-27.

25. Schittny JC, Miserocchi G, Sparrow MP. Spontaneous peristaltic airway contractions propel lung liquid through the bronchial tree of intact and fetal lung explants. Am J Respir Cell Mol Biol 2000;23:11-8.

26. von Mutius E. Environmental factors influencing the development and progression of pediatric asthma. J Allergy Clin Immunol 2002;109:525S-32S

27. Celedon JC, Litonjua AA, Ryan L, Platts-Mills T, Weiss ST, Gold DR. Exposure to cat allergen, maternal history of asthma, and wheezing in first 5 years of life. Lancet 2002;360:781-2

28. Lannero E, Wickman M, Pershagen G, Nordvall L. Maternal smoking during pregnancy increases the risk of recurrent wheezing during the first years of life (BAMSE). Respir Res 2006;7:3.
29. Wills-Karp M. Interleukin-13 in asthma pathogenesis. Immunol Rev 2004;202: 175-90.

30. Zhu Z, Homer RJ, Wang Z, Chen Q, Geba GP, Wang J, et al. Pulmonary expression of interleukin-13 causes inflammation, mucus hypersecretion, subepithelial fibrosis, physiologic abnormalities, and eotaxin production. J Clin Invest 1999;103:779-88.

31. Spinozzi F, Agea E, Russano A, Bistoni O, Minelli L, Bologni D, et al. CD4+IL13+ T lymphocytes at birth and the development of wheezing and/or asthma during the 1st year of life. Int Arch Allergy Immunol 2001;124:497-501.

32. Dealtry GB, Clark DE, Sharkey A, Charnock-Jones DS, Smith SK. Expression and localization of the Th2-type cytokine interleukin-13 and its receptor in the placenta during human pregnancy. Am J Reprod Immunol 1998;40:283-90.

33. Williams TJ, Jones CA, Miles EA, Warner JO, Warner JA. Fetal and neonatal IL-13 production during pregnancy and at birth and subsequent development of atopic symptoms. J Allergy Clin Immunol 2000;105:951-9.

34. Ito I, Laporte JD, Fiset PO, Asai K, Yamauchi Y, Martin JG, et al. Downregulation of a disintegrin and metalloproteinase 33 by IFN-[gamma] in human airway smooth muscle cells. J Allergy Clin Immunol 2007;119:89-97.

35. Hegde PS, White IR, Debouck C. Interplay of transcriptomics and proteomics. Curr Opin Biotechnol 2003;14:647-51

36. Richter A, Puddicombe SM, Lordan JL, Bucchieri F, Wilson SJ, Djukanovic R, et al. The contribution of interleukin (IL)-4 and IL-13 to the epithelialmesenchymal trophic unit in asthma. Am J Respir Cell Mol Biol 2001;25: 385-91.

37. Have-Opbroek AA. Lung development in the mouse embryo. Exp Lung Res 1991; 17:111-30.

38. Perl AK, Whitsett JA. Molecular mechanisms controlling lung morphogenesis. Clin Genet 1999;56:14-27.

\section{Availability of Journal back issues}

As a service to our subscribers, copies of back issues of The Journal of Allergy and Clinical Immunology for the preceding 5 years are maintained and are available for purchase until inventory is depleted. Please write to Elsevier Inc, Subscription Customer Service, 3251 Riverport Lane, Maryland Heights, MO 63043, or call (800) 654-2452 or (314) 447-8871 for information on availability of particular issues and prices. 


\section{METHODS}

\section{Collection of HELs}

The collection and use of HEL tissues (7-9 weeks postconception) was carried out from women undergoing first trimester termination of pregnancy with informed written consent and ethical approval from the Southampton and South West Hampshire Joint Local Research Ethics Committee . Human embryonic/fetal tissue was collected, staged, and processed as described previously. ${ }^{\text {E1 }}$ HEL tissue was either freshly homogenized or used for explant culture (see below in sections 'Homogenization of tissue and RNA extraction' \& 'HEL explant culture'); fresh samples were homogenized directly or dissected into tubular and mesenchymal structures before RNA extraction using TRIzol Reagent according to the manufacturer's instructions.

\section{Harvesting of mouse tissue}

Pathogen-free outbred MF1 mice (age 6 weeks; Harlan UK Limited, Bicester, UK) were time-mated by detection of a vaginal plug. This day was taken as E0. Pregnant mice between E10 and 20, newborn mice, and juvenile mice were killed by using a schedule 1 method (cervical dislocation). Gravid uteri were removed under sterile conditions and embryos killed according to a schedule 1 method (neural tube dissection, cervical dislocation). Maternal adult, embryonic, and postpartum lungs (Fig E1), hearts, and brains were dissected under a dissecting microscope (LEICA WILD M3Z, Wetzlar, Germany) in a laminar flow hood. The dissected lungs, hearts, and brains were then directly homogenized in TRIzol Reagent (Invitrogen, Paisley, UK) and RNA extracted from 3 to 9 organ samples per time point according to the TRIzol Reagent protocol.

\section{Mouse sensitization, mating, and exposure experiments}

The effect of a maternal environment on the offspring from mouse mothers with and without allergy was studied in $\mathrm{A} / \mathrm{J}$ mice that had the asthma susceptibility locus ( $B h r l)$, which is syntenic to human ADAM33. In vivo exposure studies were performed at the Ford Motor Co Fund Exposure Facility, Eugene Applebaum College of Pharmacy and Health Sciences, at Wayne State University, Detroit, Mich, after approval by the Institutional Animal Investigation Committee. Specific pathogen-free 5-week-old male and female inbred A/J mice (Harlan-Sprague Dawley, Inc, Indianapolis, Ind) were maintained throughout the experiment on low-dust corn cob bedding in highefficiency particulate-filtered air with free access to filtered water and a standard rodent diet.

Female mice were sensitized by intraperitoneal injection with $0.2 \mathrm{~mL} 0.9 \%$ sterile isotonic saline containing $10 \mu \mathrm{g}$ ovalbumin and $2 \mathrm{mg}$ aluminum hydroxide at day 21 and again at day 7 before the time of mating. Pregnancy was confirmed by increased maternal weight. Days postconception were confirmed by using standardized charts of maternal weight change and of fetal length and appearance. ${ }^{\mathrm{E} 2}$

After mating, the female mice were exposed to either saline (control) or ovalbumin ( $1 \% \mathrm{wt} / \mathrm{vol}$ in sterile isotonic saline) aerosols in a nose-only exposure system (CH Technologies, Inc, Westwood, NJ). Aerosols were generated by using collision nebulizers that provide a relatively monodispersed aerosol of $0.25 \mu \mathrm{m}$ mean aerodynamic diameter and diluent air, adjusted to provide an aerosol concentration of $25 \mathrm{mg}$ ovalbumin $/ \mathrm{m}^{3}$. The aerosol was monitored by using a DUSTTRAK Aerosol Monitor (TSI Inc, Shoreview, Minn). Diluent air was chemical and high-efficiency particulate-filtered with relative humidity controlled to $45 \%$ to $55 \%$. Exposures were conducted for a period of 1 hour per day, 3 days per week, for 3 weekly cycles.

Pregnant mice were anaesthetized with sodium pentobarbital $(50-60 \mathrm{mg} / \mathrm{kg}$ body weight, intraperitoneally) for the removal of the embryos and harvesting of maternal lung tissue. Embryo and newborn tissues were harvested after killing by a schedule 1 method. The lungs from day 15 , days 17 to 19 postconception, and 3 to 5 days post partum were removed under a dissecting microscope and collected in RNAlater (catalogue no. R0901; Ambion, Inc; Sigma Chemical Co, St Louis, Mo), stored and shipped at $4{ }^{\circ} \mathrm{C}$, and then stored at $-20^{\circ} \mathrm{C}$ until RNA extraction. Tissue preserved in RNAlater was homogenized in TRIzol Reagent for RNA extraction and RT-qPCR according to the protocol described.
To confirm inflammation of the lung in ovalbumin-exposed female mice, animals that failed to become pregnant were used to assess lung inflammation by BAL fluid recoveries of inflammatory cells 24 hours after the second and third weekly 3-daily cycles of saline and ovalbumin exposure (Fig E2). Ventilated lungs of anaesthetized mice were first perfused with warm isotonic saline $\left(37^{\circ} \mathrm{C}\right)$ via the pulmonary artery to remove blood components, followed by 5 serial BALs with $0.8-\mathrm{mL}$ aliquots of $\mathrm{PBS}\left(37^{\circ} \mathrm{C}\right.$; $\left.\mathrm{pH} 7.4\right)$ containing 3 $\mathrm{mmol} / \mathrm{L}$ EDTA. The resulting cell populations were subjected to differential analyses by staining with modified Wright stain for identification of macrophages, lymphocytes, neutrophils, and eosinophils. Results were reported as total BAL-recovered cells.

\section{Homogenization of tissue and RNA extraction}

Immediately after harvesting, mouse organs were homogenized (ribolysed) in Lysing Matrix D impact-resistant 2.0-mL tubes containing 1.4-mm ceramic spheres (Qbiogene, Cambridge, UK) and $1 \mathrm{~mL}$ TRIzol Reagent (Invitrogen, Paisley, UK) using a Hybaid RiboLyser Cell Disrupter (Thermo Life Sciences, Hybaid, UK) at speed setting 6.0 for 40 seconds. Tubes were cooled on ice for 2 minutes and incubated at room temperature for 5 minutes. HELs were dissected under a dissecting microscope in a laminar flow cell culture cabinet. One to 3 small pieces of HEL lung tissue were placed into $250 \mu \mathrm{L}$ TRIzol Reagent in $0.5 \mathrm{~mL}$ RNase-free and DNAse-free Eppendorf microtubes (SigmaAldrich, Gillingham, UK; or STAR LAB, Milton Keynes, UK) containing 3 to 5 ceramic spheres from the Lysing Matrix D tubes. Tissue was ribolysed in the Hybaid RiboLyser at speed setting 6.0 for 10 seconds, then cooled on ice for 2 minutes and incubated at room temperature for 5 minutes. The homogenate was processed for RNA extraction by using the TRIzol Reagent protocol. To remove trace contamination by genomic DNA, all samples were treated with DNase by using DNA-free (Ambion, Warrington, UK). RNAwas assessed for quality and quantity by using a spectrophotometer (Nanodrop Technologies, Wilmington, De) and then stored at $-80^{\circ} \mathrm{C}$ until reverse transcription.

\section{Reverse transcriptase assay and RT-qPCR}

RNA was reverse transcribed to cDNA as template for the quantitative PCR by using the Precision Reverse Transcription kit protocol (PrimerDesign Ltd, Southampton, UK). RT-qPCR was performed according to the Precision qPCR Mastermix protocol (PrimerDesign Ltd). Forward and reverse primers (MWG-BIOTECH, Ebersberg, Germany) and the probes (Oswell, Southampton, UK) and complete RT-qPCR assays (PrimerDesign Ltd) were used for Adam33, $\alpha$ Sma, ADAM33, and $\alpha S M A$ as previously described ${ }^{\mathrm{E} 3}$ or were newly designed (Table E1). Relative gene expression was analyzed by using the $\Delta \Delta \mathrm{C}_{\mathrm{T}}$ method relative to the geometric mean of 3 HKGs (based on geNorm analysis, see below in 'geNorm analysis'): Gapdh, Atp5b, and $C y c l$ in the mouse, and $A C T I N-\beta$ (ACTB) in the human tissue.

\section{geNorm analysis}

To establish the ideal reference genes during mouse embryonic development, geNorm analysis was performed by using the geNorm $H K G$ Selection Kit (PrimerDesign Ltd, Southampton, UK) for 12 different candidate reference genes (Table E2). geNorm Analysis Software ${ }^{\mathrm{E} 4}$ is a Microsoft Excel applet that is freely available and can be downloaded from the geNorm webpage (http://medgen.ugent.be/ jvdesomp/genorm/). It was designed to identify optimum $H K G s$, and hence to generate a measure of stability for each gene. This measure relies on the principle that, regardless of the conditions, the expression ratio of 2 normalizing genes will remain constant in all samples. Hence, any variation in expression ratio between the 2 is indicative of 1 or both genes being variably expressed. On the basis of the stability of each $H K G$, geNorm software also predicts the number of measured HKGs that are required to achieve optimum normalization.

Twelve of the most commonly used HKGs (Table E2) were measured, and geNorm analysis ${ }^{\mathrm{E} 4}$ was performed to reveal the stability expression of each gene during all stages of mouse lung development to be able to study Adam33 mRNA expression with the best normalizing genes. geNorm analysis compares the ratio of the ratio of control genes in different samples to find those that are most stable, as previously described. ${ }^{\text {E4 }}$ Total mRNA $1 \mu \mathrm{g}$ from 44 mouse lung samples, 2 from each developmental time point 
(E11-19, post partum day [P] 1-59, and adult mouse [AM]) were reverse-transcribed. RT-qPCR was performed by using 12 different $H K G$ PerfectProbe gene detection kits (PrimerDesign Ltd, Southampton, UK). All plates (in total, twelve 96-well PCR plates) were prepared at the same time, with each plate containing 1 different reference gene. All data points were run in duplicate according to the appropriate amplification protocol as described. The $\mathrm{Ct}$ values (number of PCR cycles $[\mathrm{C}]$ that elapse before the threshold $[\mathrm{t}]$ is reached) were transferred into a Microsoft Excel sheet and transformed into relative quantification data by using the $\Delta \mathrm{C}_{\mathrm{T}}$ method by subtracting the highest $\mathrm{Ct}$ value from all other $\mathrm{Ct}$ values for each gene measured. The resulting $\Delta \mathrm{C}_{\mathrm{T}}$ values, with the highest becoming 0 and all the others becoming less than 0 , were then exponentially transformed by using the equation.

$$
2^{(-\Delta \mathrm{CT})}
$$

This results in the expression of the data relative to the expression of the least expressed gene. An input file for geNorm analysis was prepared in Microsoft Excel with the first column containing the sample names and the first row containing the 12 different reference gene names. The file was saved in the InputData directory of geNorm. After closing all running Microsoft Excel files, the geNorm applet was started by clicking on the geNorm.xls file and enabling the prompted macro in Excel. The data input file was loaded, and automated analysis was performed. The first geNorm chart was generated, showing the average expression stability values of remaining control genes and the most stable expressed genes (Fig E3, A). After clicking the automated analysis icon for a second time, a second geNorm chart was generated, showing the determination of the optimal number of control genes for normalization (Fig E3, B). The 12 HKGs were rated for the average expression stability (M), with the most stable producing the lowest M value (Fig E3, A). The top $2 H K G s$ cannot be ranked in order because a gene ratio is required to calculate gene stability. The pairwise variation analysis $(\mathrm{V})$ in normalizing signal $\left(\mathrm{NF}_{\mathrm{n}}\right)$ was also calculated for the data set by using geNorm (Fig E3, $B$ ). This measures the degree of variation in normalization signal that is achieved by using $n$ control genes compared with $n+1$, with genes added stepwise into the analysis in the order of their gene stability rankings. The stability of the normalization signal improves up to the addition of the sixth gene and then deteriorates as the 6 least stable genes are added to the analysis.

The 4 mouse HKGs Gapdh, Atp5b, Cycl, and succinate dehydrogenase complex subunit A ( $S d h a$ ) were most stably expressed (lowest average stability $\mathrm{M}$ ) in the developing lungs (Fig E3, $A$ ) but also in the hearts and brains (data not shown). The combination of 6 to 7 HKGs was the optimal number of control genes for normalization, reaching a pairwise variation $\mathrm{V}$ of less than 0.15 ; however, the combination of 3 to 4 HKGs also showed an acceptable low variability of less than 0.25 (Fig E3, B). The 3 most stably expressed $H K G s$ were found to be Gapdh, Atp5b, and $C y c l$, and these were used for normalization of Adam 33 and $\alpha$ Sma mRNA in the murine lungs.

\section{Protein extraction and analysis}

Protein from mouse lung tissue was isolated from the organic phase left over after RNA extraction by using the TRIzol Reagent method, following the manufacturer's protocol. First the DNA was precipitated by adding $0.3 \mathrm{~mL}$ $100 \%$ ethanol per $1 \mathrm{~mL}$ TRIzol Reagent used for the initial homogenization. The resulting protein pellet was processed by drying the pellet in a hot block (DRI-BLOCK DB-2P; TECHNE; Barloworld Scientific Ltd, Stone, UK) at $50^{\circ} \mathrm{C}$ for 5 minutes and dissolving in $200 \mu \mathrm{L} 1 \mathrm{x}$ SDS sample buffer by pipetting up and down. Complete dissolution of the protein pellet required incubating the sample at $50^{\circ} \mathrm{C}$ for about 20 minutes and sonication in a MSE Soniprep 150 (MSE Limited, London, UK) for about 30 seconds. After this, the samples were centrifuged at $3000 \mathrm{rpm}$ for 2 minutes.

Protein samples were separated by SDS-PAGE using $12.5 \%$ polyacrylamide gels and Western blotted as previously described. ${ }^{\mathrm{E5}}$ The membranes were stained with Ponceau S solution (Sigma-Aldrich Ltd, Dorset, UK) and assessed for total protein loading followed by immunostaining. The primary goat antibody against Adam33 protein (AF2434; R\&D Systems Europe Ltd, Abingdon, UK) was diluted 1 to 1000 in $10 \mathrm{~mL}$ blocking buffer, and the membrane was incubated at room temperature for 90 minutes. Secondary rabbit antigoat antibody_horseradish peroxidase-linked (1 to 2000; P0449; Dako
Ltd, Ely, UK) was made up 1 to 2000 in $10 \mathrm{~mL}$ blocking buffer added to the membrane, which was incubated for 60 minutes. After appropriate washings, antibody binding was visualized by using Amersham Enhanced Chemiluminescence Plus Western Blotting Detection System (GE Healthcare, UK Limited, Little Chalfont, UK) according to the manufacturer's instructions. Luminescence was detected by using Amersham Hyperfilm Enhanced Chemiluminescence (GE Healthcare, UK Limited). Once probed with an Adam33 antibody, the membranes were stripped of all bound antibodies by using Western blot stripping buffer to blot for Actin- $\beta$ as a loading control. The blot was blocked and reprobed with the primary goat anti-Actin- $\beta$ antibody ( 1 to 1000 ; ab8229; Abcam plc, Cambridge, UK) and secondary rabbit antigoat antibody-horseradish peroxidase-linked (1 to 2000; (P0449; Dako UK Ltd, Ely, UK), as described. The films were scanned, and relative Adam33 protein intensity was analyzed by using ImageJ (US National Institutes of Health, Bethesda, Md).

\section{HEL explant culture}

Human embryonic/fetal lungs with a developmental age between 7 and 9 weeks postconception were cut into pieces of tissue 1 to $2 \mathrm{~mm}$ and placed onto a polyester membrane of clear transwells that were inserted into 24 Well Clusters/Case (Costar Transwell 3470-Clear; Corning Inc, Corning, NY) HEL tissue pieces were embedded in 50 to $60 \mu \mathrm{L}$ Growth Factor Reduced Matrigel Matrix (BD Biosciences, Oxford, UK) with $340 \mu \mathrm{L}$ serum-free medium in the wells. The explants were incubated at $37^{\circ} \mathrm{C}$ and $5 \% \mathrm{CO}_{2}$ for 6 to 18 days. Medium in the wells was collected and replaced every third day. Time-lapse microscopy was performed for 8 days to demonstrate branching morphogenesis.

Using this newly developed explant culture system, HELs were cultured in the presence of the $\mathrm{T}_{\mathrm{H}} 2$ cytokine recombinant human IL-13 at $1 \mathrm{ng} / \mathrm{mL}$ ( $\mathrm{R} \& \mathrm{D}$ Systems, Inc, Abingdon, UK). The tissue was harvested into TRIzol reagent for RNA extraction and RT-qPCR at 6,12, and 18 days. Phase contrast images were taken at days $0,6,12$, and 18 by using a LEICA DM IRB inverted microscope (Leica Microsystems GmbH, Wetzlar, Germany).

\section{Statistics}

Data analyses were performed by using SigmaStat and SigmaPlot (Systat Software Inc, Hounslow, UK). All data comparing 2 groups were analyzed by using a parametric Student $t$ test. Where the test failed normality criteria, nonparametric tests (Mann-Whitney rank-sum test or Wilcoxon rank-sum test) of statistical significance were performed. Data of more than 2 groups that were normally distributed were compared by using 1-way ANOVA and a multiple comparison Bonferroni $t$ test. Where the test for normality failed, KruskalWallis 1-way ANOVA on ranks and multiple comparisons were performed by using either the Student-Newman-Keuls or the Dunnett method. Significance was reached when $P \leq .05$.

\section{RESULTS \\ Adam33 mRNA expression in mouse embryonic, fetal, juvenile, and adult tissues}

Outbred MF1 mice were chosen for ease of mating and the high number of offspring per litter. Lungs, hearts, and brains were dissected from mouse embryos/fetuses on E11 to 19 and juvenile mice from P1 (Fig E1), 2, 9, 16, 23, 30, 37, 44, 52, and 59, and adult mice. RNA was extracted for gene analysis with RTqPCR. Initially Adam 33 mRNA expression in the lungs was analyzed relative to either $18 S r R N A$ (Fig E4, A) or Gapdh (Fig E4, B) mRNA, both of which are commonly used genes for normalization. Data analysis revealed that normalization with either gene produced a similar expression profile, with Adam33 mRNA increasing during gestation; however, there were inconsistencies in the fold increase and expression profile, especially around the time of birth and the neonatal period. Because embryonic development is a complex process during which significant changes in gene expression occur, we were concerned that these 
inconsistencies were a result of changes in expression of the $H K G s$. For this reason, we established which $H K G s$ were most stably expressed during all stages of mouse lung development by using geNorm analysis to enable accurate gene quantification.

Twelve of the most commonly used HKGs (Table E2) were measured, and geNorm analysis ${ }^{\mathrm{E} 4}$ was performed to reveal the expression stability of each gene during different stages of mouse lung development. The 4 most stably expressed genes (lowest average stability $\mathrm{M}$ ) in developing mouse lungs were found to be Gapdh, Atp5b, Cycl, and Sdha (Fig E3, A); similar results were obtained for hearts and brains. The analysis revealed that combinations of 6 to $7 \mathrm{HKGs}$ was the optimal number of control genes for normalization, reaching a pairwise variation $(\mathrm{V})$ of less than 0.15 ; however, a combination of 3 to $4 H K G s$ also showed an acceptable low variability of less than 0.25 (Fig E3, B).

When the 3 most stably expressed HKGs (Gapdh, Atp5b, $C y c 1$ ) were used for normalization of Adam33 mRNA in the murine lungs, it could be seen that Adam33 expression increased in significant steps during mouse lung development (Fig 5, A). These changes corresponded to the stages of normal lung development (Fig 5, D; Fig E1), with the greatest increases in Adam33 mRNA expression from the early embryonic stage and lung bud formation (ED11) to the pseudoglandular stage (ED12-16) and again from saccular $($ ED18, 19) to the alveolar (P5-30) and adult stage (AM; $P<.001) . \alpha$ Sma mRNA expression showed a similar pattern, with a significant increase in the early stage of embryonic lung development and post partum (Fig 5, B). In contrast, the transcription factor, forkhead box
A1 (Foxal), another important gene in lung development, ${ }^{\mathrm{E} 6}$ showed a much lower expression relative to Adam33 and no incremental changes during lung development. ${ }^{\mathrm{E} 7}$ In comparison with developing lungs, Adam 33 and $\alpha$ Sma mRNA were much lower and had a different and much flatter pattern of expression in tissue from developing heart and brain, suggesting differential regulation in these 2 organs (Fig E5, $A-D$ ).

\section{REFERENCES}

E1. Hanley NA, Hagan DM, Clement-Jones M, Ball SG, Strachan T, Salas-Cortes L, et al. SRY, SOX9, and DAX1 expression patterns during human sex determination and gonadal development. Mech Dev 2000;91:403-7.

E2. Foster HL, Small JD, Fox JG. The mouse in biomedical research: normative biology, immunology, and husbandry. Orlando: Academic Press, Inc; 1983.

E3. Powell RM, Wicks J, Holloway JW, Holgate ST, Davies DE. The splicing and fate of ADAM33 transcripts in primary human airways fibroblasts. Am J Respir Cell Mol Biol 2004;31:13-21.

E4. Vandesompele J, De PK, Pattyn F, Poppe B, Van RN, De PA, et al. Accurate normalization of real-time quantitative RT-PCR data by geometric averaging of multiple internal control genes. Genome Biol 2002;3:RESEARCH0034

E5. Haitchi HM, Powell RM, Shaw TJ, Howarth PH, Wilson SJ, Wilson DI, et al. ADAM33 expression in asthmatic airways and human embryonic lungs. Am J Respir Crit Care Med 2005;171:958-65.

E6. Wan H, Dingle S, Xu Y, Besnard V, Kaestner KH, Ang SL, et al. Compensatory roles of Foxa1 and Foxa2 during lung morphogenesis. J Biol Chem 2005;280:13809-16.

E7. Haitchi HM, Yoshisue H, Ribbene A, Wilson SJ, Holloway JW, Bucchieri F, et al. Chronological expression of ciliated bronchial epithelium 1 during pulmonary development. Eur Respir J. In press 2008.

E8. Have-Opbroek AA. Lung development in the mouse embryo. Exp Lung Res 1991;17:111-30.

E9. Perl AK, Whitsett JA. Molecular mechanisms controlling lung morphogenesis. Clin Genet 1999;56:14-27. 


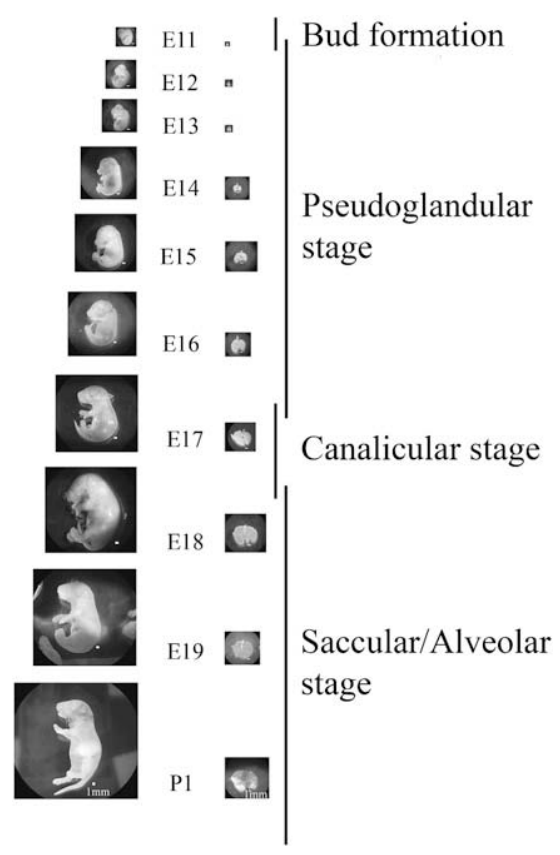

FIG E1. Images of whole mouse embryos and fetuses $(E)$ from day 11 to 19 and newborn mouse post partum $(P)$ day 1 with dissected lungs (white bar $=1 \mathrm{~mm}$ ) showing different histologic stages of lung development in the mouse. ${ }^{\mathrm{E}, \mathrm{Eg}}$ 


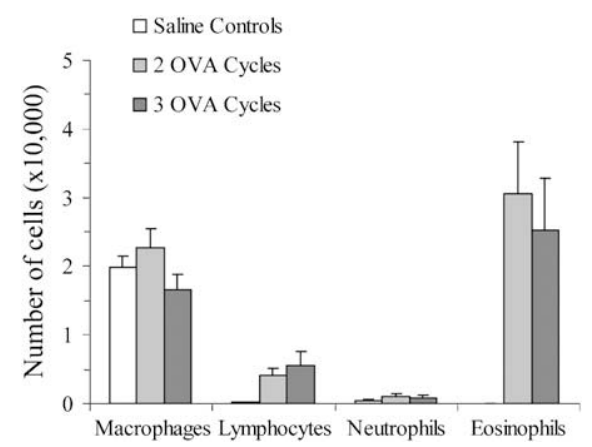

FIG E2. Recovery of inflammatory cells from bronchoalveolar lavage fluid from female adult $A / J$ mice 24 hours after completion of 2 and 3 cycles of ovalbumin (OVA) exposure compared to saline exposures (control). Results represent means \pm SEMs $(n=3-6)$. 

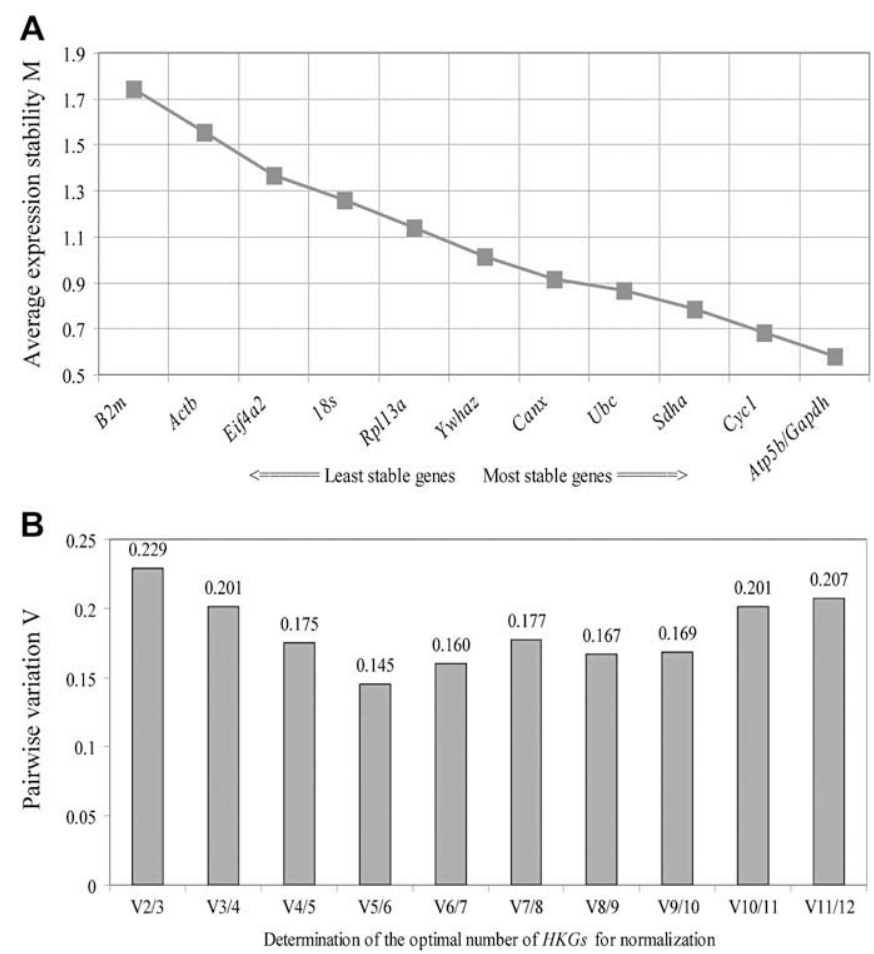

FIG E3. geNorm analysis ${ }^{\mathrm{E} 4}$ from 24 mouse lung samples (in duplicate) from all stages of embryonic lung development using 12 different commonly used HKGs (See Table E2). A, Determination of the most stably expressed genes with the lowest average expression stability $(M)$ value. B, Determination of the optimal number of control genes derived by pairwise variation $(V)$ analysis between the normalization factors of $n$ and $n+1$ genes. 

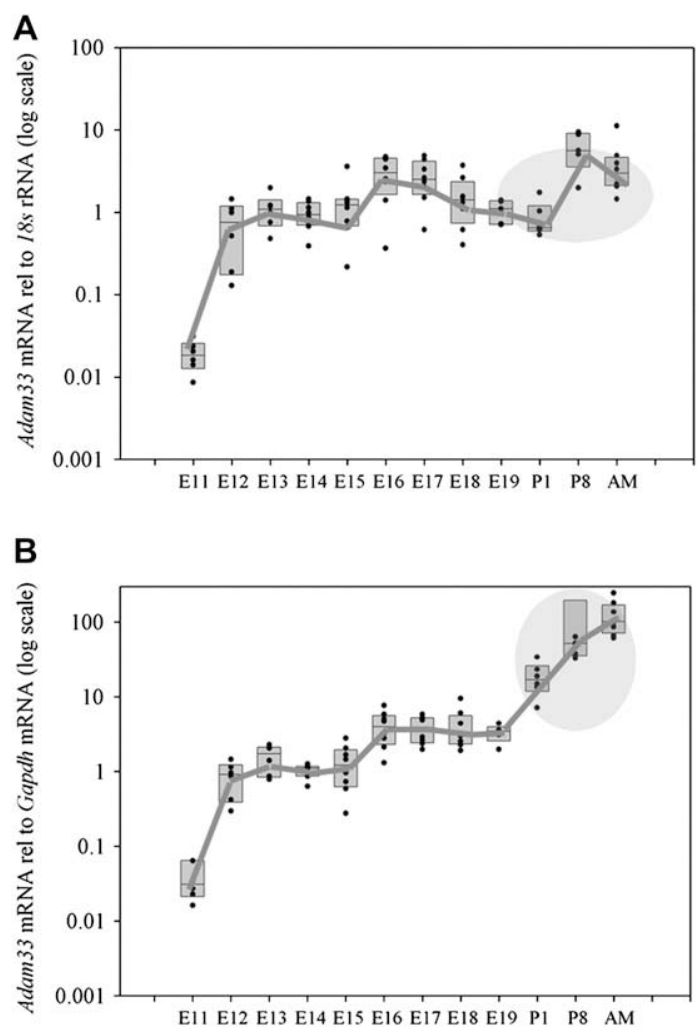

FIG E4. Adam33 mRNA expression (log scale) (A) relative to 18S rRNA and (B) relative to Gapdh mRNA in vivo in lungs harvested from embryonic/fetal $(E)$ days 11 to 19 , post partum $(P)$ days 1 and 8 , and adult MF1 mice. The shaded area highlights the region of difference. 
A
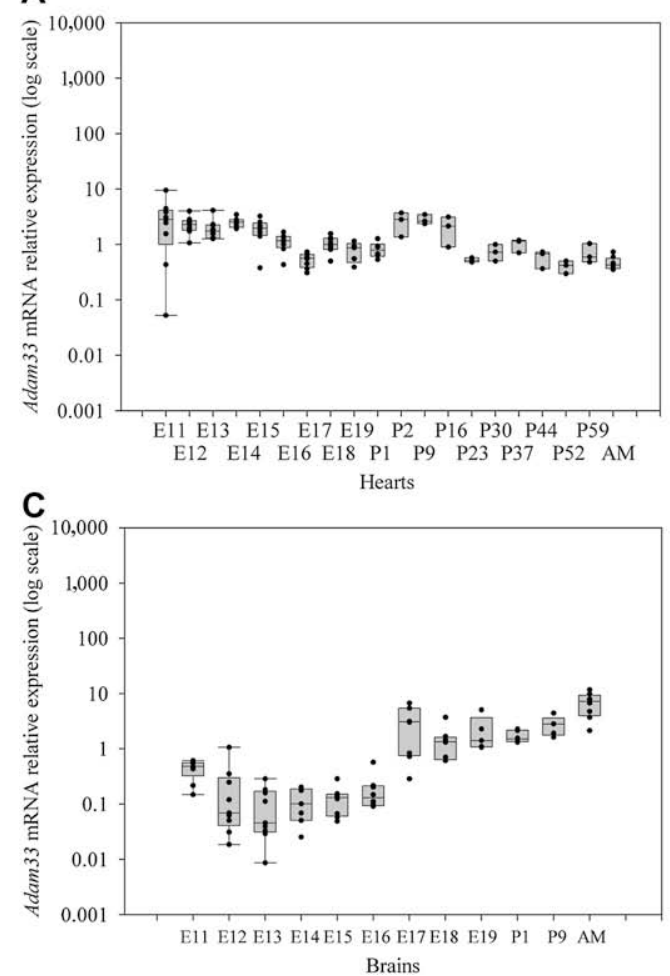

B

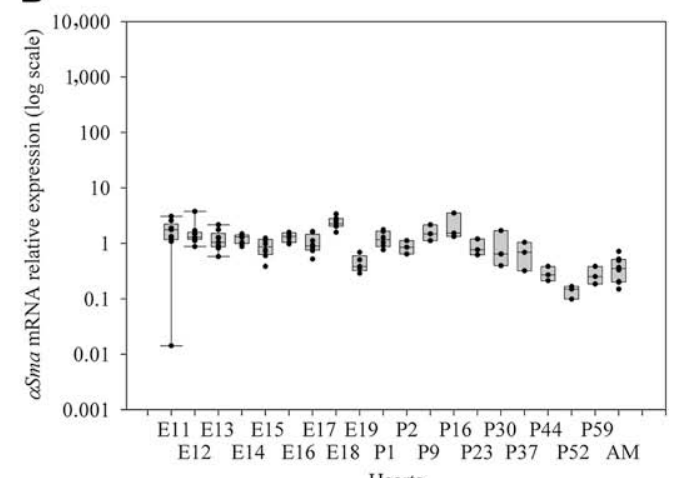

D

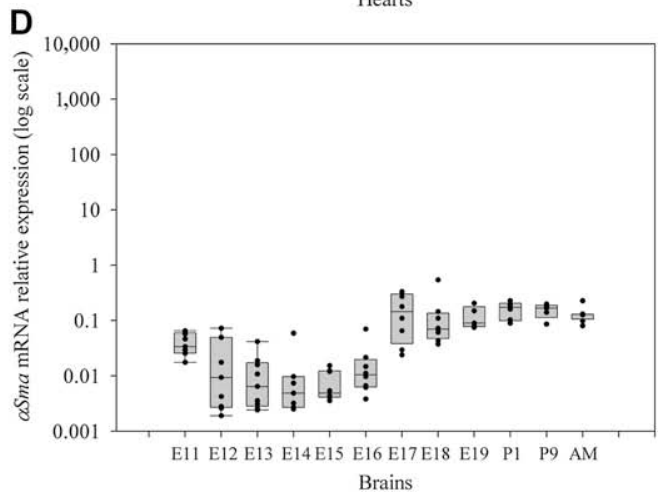

FIG E5. Adam33 and $\alpha$ Sma mRNA relative to HKGs expression (log scale) in vivo in mouse (A and C) hearts and (B\&D) brains harvested from embryonic/fetal $(E)$ days 11 to 19 , post partum $(P)$ days 1 to 59 , and adult (AM) MF1 mice. 


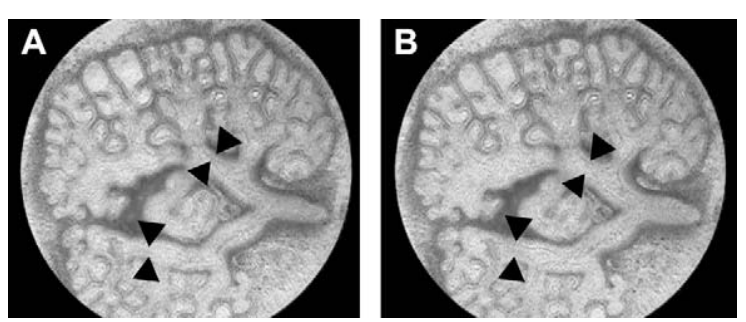

FIG E6. Real -time snap shots of mouse embryonic day $11 / 12$ lungs cultured for 48 hours showing spontaneous (A) contraction and (B) relaxation of the primitive airways (black arrows). Contractions occurred every 40 seconds. 
TABLE E1. RT-qPCR primer and probes

Target (accession no.)

Human

ADAM33

(NM_025220)

Alpha smooth muscle actin ( $\alpha S M A)$

(NM_001613)

$A C T I N-\beta(A C T B)$

Mouse (Mus musculus)

Adam33

(NM_033615.1)

Alpha smooth muscle actin $(\alpha S m a)$

(NM_007392)

Glyceraldehyde 3-phosphate dehydrogenase (Gapdh)

Mitochondrial ATP synthase beta subunit (Atp5b)

Cytochrome $\mathrm{C} 1(\mathrm{Cycl})$

12 Different candidate reference genes from geNorm Housekeeping Gene Selection Kit
Forward primer (F): 5'-GGCCTCTGCAAACAAACATAATT-3'

Reverse primer (R): 5'-GGGCTCAGGAACCACCTAGG-3'

Probe (P): 5'-CTTCCTGTTTCTTCCCACCCTGTCTTCTCT-3'

F: 5'-GACAGCTACGTGGGTGACGAA-3'

R: 5'-TTTTCCATGTCGTCCCAGTTG-3'

P: 5'-TGACCCTGAAGTACCCGATAGAACATGGCT3'

F: PrimerDesign

R: PrimerDesign

P: PerfectProbe ${ }^{\mathrm{TM}}$, PrimerDesign

F: 5'-GCAGGATCTCAGTCGCATCA-3'

R: 5'-GGCGCCACTGTAGGAAAGC-3'

P: 5'-TCAGGACGCAAACGAAACGCTCTGT-3'

F: 5'-TGAAGAGGAAGACAGCACAGC-3'

R: 5'-GGAGCATCATCACCAGCGAA-3'

P: 5'-CAGAGCCCAGAGCCATTGTCGCAC-3'

F: PrimerDesign

R: PrimerDesign

P: PerfectProbe, PrimerDesign

F: PrimerDesign

R: PrimerDesign

P: PerfectProbe, PrimerDesign

F: PrimerDesign

R: PrimerDesign

P: PerfectProbe, PrimerDesign

F: PrimerDesign

R: PrimerDesign

P: PerfectProbe, PrimerDesign
Fam

Fam

Fam

Fam

Fam

Fam

Fam

Fam

Fam 
TABLE E2. HKGs used for geNorm analysis

Accession no.

Mus musculus; sequence definition

NM_007393

Actin, $\beta$, cytoplasmic (Actb), mRNA

NM_001001303

Glyceraldehyde 3-phosphate dehydrogenase (Gapdh), mRNA

NM_019639

NM_009735

Ubiquitin $\mathrm{C}(U b c)$, mRNA

NM 011740

$\beta$-2 Microglobulin (B2m), mRNA

NM_009438

NM_007597

NM_025567

NM_023281

Phospholipase A2 (Ywhaz), mRNA

Ribosomal protein L13a (Rpll3a), mRNA

Calnexin (Canx), mRNA

Cytochrome C1 (Cycl), mRNA

Succinate dehydrogenase complex subunit A (Sdha), mRNA

$\mathrm{X} 00686$

$18 s$ rRNA gene

NM_013506

Eukaryotic translation initiation factor 4A2 (Eif4a2), mRNA

NM_016774

Mitochondrial ATP synthase beta subunit (Atp5b), mRNA 